\title{
O trânsito entre culturas e as práticas de comunicação e educação
}

Atual diretor do Centro de Comunicação e Educação da Universidade Nacional de La Plata e diretor de Educação Superior da Província de Buenos Aires, o pensador argentino Jorge Huergo dedica-se a refletir sobre as relações entre esses dois campos: comunicação e educação. Nesta entrevista, concedida durante uma visita ao Departamento de Comunicações e Artes da ECA-USP, explicou como seu trabalho com educação popular, nas áreas rural, aborígine e urbana, está ligado ao reconhecimento de mundo cultural. Enfatiza o fato de realizá-lo com práticas de comunicação e educação, significando um distanciamento das concepções iluministas da educação, em favor de um trabalho e de um encontro cultural, no qual se pode reconhecer o mundo cultural do outro, as identidades, as formas de saber, de circulação dos saberes, o vínculo com os espaços, as formas de educação sociais e a sensibilidade. Huergo demonstra como isso nos mobiliza e nos põe em relação com os jovens, com as culturas juvenis e suas manifestações - suas formas de sociabilidade e de percepção. "Comunicação e educação tem muita relação com essa vinculação entre o mundo cultural e o horizonte político", afirma. "E tem muito a ver com a criação de espaços e de possibilidade de comunicação através da formação, em um contexto composto de sentidos, de meios de comunicação e tecnologia”, complementa.

Por Maria Cristina Castilho Costa

C \& E: Gostaríamos que você se apresentasse para os nossos leitores.

Jorge Huergo: Estudei Filosofia e Pedagogia em La Plata, na Argentina. Quando terminei minha escola secundária, vivi cinco anos em uma comunidade aborígine mapuche. Comecei a trabalhar com alfabetização em comunidades populares, praticando algo parecido com o método de Paulo Freire. Depois trabalhei com educação e, dentre muitas experiências interessantes, o melhor foi fazer parte de um grupo fundador de duas escolas para adultos: uma para trabalhadores da saúde e outra para detentos da prisão de Olmos - uma das maiores da Argentina. Logo depois comecei a trabalhar na Universidade de La Plata, em 1992. Ali fundei a cátedra de Comunicação e Educação, assim como o Centro de Comunicação e Educação e o programa de pesquisa com essa mesma temática, dos quais ainda sou diretor. Paralelamente, desenvolvi atividades vinculadas à comunicação de educação popular, nas áreas rural, aborígine e urbana. Atualmente sou diretor de Educação Superior da província de Buenos Aires e professor em distintas universidades da Argentina e da América Latina. 
comunicação \& educação • Ano XIII • Número 1 • jan/abr 2008

C \& E: Quais são os princípios do seu trabalho com os indígenas?

Huergo: Fundamentalmente, trabalho com o reconhecimento de mundo cultural, não somente com os indígenas, mas, de maneira geral, com práticas de comunicação e educação. Isso significa um distanciamento das concepções iluministas da educação, em favor de um trabalho e de um encontro cultural, no qual se pode reconhecer o mundo cultural do outro, as identidades, as formas de saber, de circulação dos saberes, o vínculo com os espaços, as formas de educação sociais, a sensibilidade. Isto nos mobiliza e nos põe em relação com os jovens, com as culturas juvenis e suas manifestações - suas formas de sociabilidade e de percepção. É o que para mim caracteriza um dos princípios gestores do trabalho com aborígines, mas também com outros grupos. No caso dos aborígines, parece-me fundamental o horizonte político no trabalho, isto é, a maneira como nós podemos abrir um espaço que seja referencial, em que se fomente a comunicação democrática e se possa pronunciar a palavra e atuar em um mundo cultural no qual se nasceu e ao qual se pertence. Comunicação e educação têm muita relação com essa vinculação entre o mundo cultural e o horizonte político. E tem muito a ver com a criação de espaços e de possibilidade de comunicação através da formação, em um contexto composto de sentidos, de meios de comunicação e tecnologia.

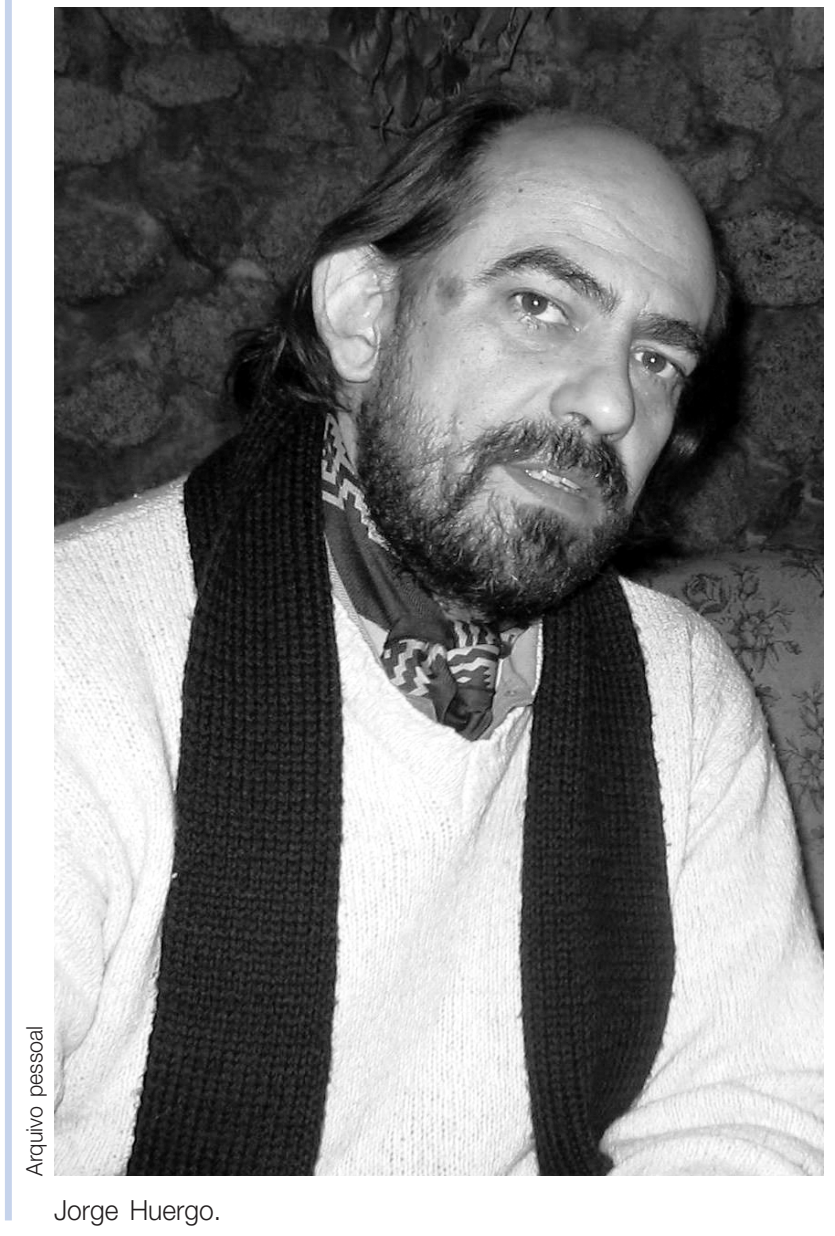

C \& E: No Brasil, e de maneira geral na América Latina, essa tradição iluminista tem realçado uma grande distinção na sociedade entre o que é cultura letrada e cultura oral. Os meios de comunicação têm colaborado para diminuir essa distância? Huergo: Os meios de comunicação não trabalham necessariamente no mundo da oralidade secundária, que não é aquela oralidade tradicional, mas de alguma forma recupera muitas questões da oralidade. O problema é incluí-los em trabalhos educativos. O perigo é quando a escola os reduz à própria lógica escolar, à gramaticalidade que tem a escola, deixando de aproveitar não somente a oralidade, mas também o caráter criativo, expressivo, produtivo dos meios dentro de um processo de formação. 
C \& E: Em uma aula magna na USP, o professor Muniz Sodré falou que hoje os meios de comunicação são educativos porque estão usando uma linguagem de persuasão. Você concorda com isso?

Huergo: O que é possível ver hoje em nossa sociedade, ao menos na Argentina, é que há muitos espaços sociais educativos diferentes além da escola, entre eles os meios de comunicação. São espaços mais reais, de organização social, midiáticos, de mercado. E mesmo o espaço escolar, assim como os outros espaços educativos, são interpelados à medida que nos reconhecemos neles e lá formamos modalidades de ver o mundo, de ler, de escrever o mundo e a própria vida. Nenhum desses espaços consegue uma hegemonia total sobre o imaginário e a identidade. O que podemos sustentar é que existem identificações múltiplas, pois todos esses espaços se interpelam e são transitórios. É interessante ver como é apropriado o conceito de Jacques Lacan a respeito das múltiplas identificações. Segundo ele, a nossa subjetividade é resultado de diferentes discursos, múltiplos discursos diante dos quais, muitas vezes, nos reconhecemos de forma transitória.

C \& E: Quando falamos em meios de comunicação, no Brasil, muitas vezes estamos nos referindo, principalmente, à televisão. Isso acontece na Argentina?

Huergo: Principalmente do interior do país. Mas também estamos nos referindo ao rádio e a um crescente uso das novas tecnologias da comunicação, como a internet. É preciso considerar ainda as diferenças de uso em relação às classes sociais. Mas o consumo televisivo é mais hegemônico, poderíamos dizer.

C \& E: Numa pesquisa com os indígenas do Mato Grosso, estudou-se como eles assistiam à televisão e como viam telenovela. Concluiu-se que eles desejavam ver como os brancos vivem, o que falam, como se sentem. No seu contato com os indigenas argentinos, o que pôde verificar da relação deles com os meios?

Huergo: Há dois anos tivemos um grande trabalho com quarenta e duas comunidades no norte da Argentina. Havia televisões em poucas casas e com uma captação de satélite curiosa. Na realidade, havia conexão com um só aparelho e aquele que tinha o aparelho-padrão era quem trocava os canais, quando desejava. Imagino que há muito disso, ver como vivem os brancos. Mas também corremos o risco de compreender isso de forma equivocada. Pode ser simplesmente uma ligação com a roupa da moda, com a distinção de determinados gostos, que são muito mais visíveis e explícitos na vida urbana. De todo modo, nós trabalhamos com comunidades rurais, não apenas urbanas. São aldeias constituídas de uma maneira muito interessante. Eram comunidades originalmente nômades, mas vivendo de forma sedentária e construindo o significado da vida com uma forte relação com o mundo. Assim, percebemos um grande abismo entre esses consumos e a vida que levam em termos de produção campesina. Para mim o espaço das culturas aborígines é algo que não podemos generalizar a partir de uma pesquisa. Há muitas características diferenciadas entre uma e outra, inclusive as formas lingüísticas. Pelo menos entre o Mapuche e o Uichi, na Argentina, são absolutamente diferentes os mo- 
dos de construir a vida cotidiana, as significações que se atribuem à família, à sociedade branca etc. $\mathrm{O}$ que nos chamou muito a atenção foi o uso que se deu ao rádio. Nós os acompanhamos na criação de uma rádio comunitária, a primeira totalmente aborígine na Argentina, com licença, legalizada. Em nosso país, lamentavelmente, pelas leis argentinas, a maioria das rádios comunitárias não tem licença para funcionar. No trabalho em questão, os grupos eram majoritariamente jovens, e muito comprometidos com a cultura tradicional. Assim, aproveitavam a rádio para que os mais velhos contassem sua experiência do passado. Chamou-nos muito a atenção os objetivos explícitos de utilizar a rádio como um espaço educativo.

C \& E: Além do conteúdo, eles conseguiram fazer um uso particular desse meio de comunicação. Foi possivel observar alguma diferença na utilização dos meios de comunicação, ou houve um espelhamento do que é feito por nós?

Huergo: Realmente, há que se ter muita atenção com isso. Esse era um dos nossos objetivos. Quando se trabalha com um meio de comunicação, costuma-se reproduzir a lógica do trabalho nos meios massivos, isto é, nos grandes meios, no mercado. Essa é uma das questões centrais no processo de produção radiofônica. Para nós era importante o objetivo de recuperar aspectos relacionados com o mundo cultural tradicional, pois, dessa forma, essa rádio não seria mera cópia de uma mídia comercial.

\section{C \& E: Isso foi alcançado?}

Huergo: Em alguns aspectos sim, em outros não, porque os mundos aborígines, hoje, não são puros. Nunca foram, mas, mais do que nunca, estão atravessados pelo processo de globalização. Entretanto, há muita mistura, muita hibridização. De qualquer maneira, há certas questões que podemos investigar, como os modos cotidianos de comunicação utilizados na rádio, os modos de ativar processos de circulação de saberes. Por outro lado, o uso do microfone, por exemplo, é difícil de desativar, porque se tornou um hábito muito conhecido. Sabe-se que o microfone é utilizado de tal maneira, e isso é muito complicado. Sempre se diz que o hábito da cultura mais visível é o que penetrará por todas as partes. Isso é muito mais difícil de transformar.

C \& E: Com relação aos novos meios de comunicação, às novas mídias, em sua opinião, eles são realmente mais inclusivos? Ou são mais elitistas?

Huergo: Acredito que no mundo atual, falo da Argentina, os novos meios são mais elitistas porque, na realidade, não há nenhum uso generalizado nem as possibilidades de se generalizar o uso dos meios digitais. Mas acredito que muitas das questões ligadas a eles possam ser mais democráticas se alcançarmos uma utilização mais ampla, garantindo maior possibilidade expressiva, criativa e produtiva do que a televisão e o rádio. Vemos como os jovens na cidade trabalham com as novas tecnologias e a potencialidade comunicativa enorme que há. Lamentavelmente, a escola muitas vezes não a considera, assim como as políticas públicas em comunicação não a levam em conta. Neste momento, na 
cidade de Buenos Aires, está sendo lançado um programa de conectividade em busca meramente das novas tecnologias digitais, relacionado com a transmissão de informação. Dessa forma não se amplia o espaço, promove-se um atraso. Isso tem muito a ver com o período de nossa história em que foram crescendo esses novos meios: o neoliberalismo. Com essa volta, esse regresso à idéia de que as inovações tecnológicas provocam um desenvolvimento social, uma vida mais feliz. Que, de fato, na educação, as inovações tecnológicas levam a uma qualidade educativa, é uma falácia. Infelizmente, nada nos faz pensar que seja assim, e, lamentavelmente, os modelos tecnicistas e tecnocráticos contribuíram para reforçar as tradições mais controladoras, mais discriminadoras. Inclusive os modelos de novos cursos e carreiras virtuais que, na realidade, são muito mais piramidais do que os cursos presenciais. Assim, os modelos de educação a distância, mesmo em instituições muito progressistas, terminam sendo excludentes em termos de quem circula por onde.

C \& E: Apesar de todo o desenvolvimento tecnológico e de escolas que reconhecem a necessidade de trabalhar a comunicação e a educação, encontramos ainda muita resistência, inclusive entre os profissionais da educação, professores, pedagogos. Isso ocorre na Argentina também?

Huergo: Há alguns grupos liberais que incorporaram mais esse assunto, vinculado às questões da cultura e, sobretudo, da cultura juvenil. De todo modo, encontro diferentes tipos de objeções: em primeiro lugar, uma espécie de menosprezo em relação ao campo da comunicação; em segundo lugar, penso também na insuficiência das políticas públicas de educação. Na realidade, essas objeções foram limitando a educação para os meios à incorporação de meios e tecnologias pela escola. Mas a escola tem muitas falhas, e a pedagogia também tem muitos desacertos em termos de como trabalhar a complexidade. Em terceiro lugar, parece-me haver outro tipo de problema, que é o temor em relação ao que produz a cultura midiática. Não acredito que seja tanto o temor do uso dos meios, mas sim da desordem que produz, da polissemia mesma da imagem, que não é a mesma do texto escrito. Em muitos casos, o professor se sente muito mais inseguro com a imagem. Com a imagem ele se sente desafiado, percebe que seus alunos são interpelados por outras linguagens e que as referências sociais que as circundam são muito mais fortes. Mas não sabem nem conceituála, nem abordá-la estrategicamente.

C \& E: Qual setor tem demonstrado mais interesse em comunicação e educação? O setor público ou o privado?

Huergo: Ao setor privado é um enorme negócio, e acredito que cresceu muito mais do que o público. Na Argentina, o Estado não se encarregou, de maneira abrangente e séria, da vinculação entre comunicação e educação. As universidades tomaram essa incumbência pouco a pouco e houve um crescimento importante em torno disso. Mas eu diria que está bastante desorganizado. O setor privado encontrou um nicho de negócio considerável. É muito forte a produção de softwares, de cursos a distância e de uma série de estratégias que 
comunicação \& educação • Ano XIII • Número 1 • jan/abr 2008

combinam comunicação e educação, as quais se transformaram em um negócio muitas vezes reconhecido pelo Estado, que o legitima. No Estado não se criaram modalidades de trabalho que ultrapassassem uma visão instrumental dos meios de comunicação, sendo apenas formas estratégicas de transmissão de informação.

C \& E: Na América Latina, quais são os países que, em sua opinião, melhor trabalham a relação entre comunicação e educação?

Huergo: Para responder a esta pergunta, eu definiria diferentes níveis de atuação. Primeiro, há o nível acadêmico, e onde melhor se está trabalhando, seguramente, é no Brasil, na Colômbia e no Chile. Do ponto de vista dos sistemas escolares, presenciei trabalhos muito interessantes na Colômbia e no México, onde também há uma atividade importante do ponto de vista acadêmico. Em um segundo nível, na Colômbia, conheci boas ações vinculando comunicação e educação com ênfase na construção da cultura de paz, porém, não uma cultura de paz que anule o conflito, mas que o assuma dialogicamente. Existe um terceiro nível, que é o da comunicação e educação popular na América Latina, e penso que é motivo para celebrar. Há novos esforços depositados na transformação de nossas sociedades. São tantas e tão diversas experiências... Penso em algumas com jovens. Vi muitíssimas na Argentina, bem interessantes. No Chile, vinculadas ao movimento dos estudantes do ensino médio, ocorrem práticas interessantíssimas de uso de internet, do blog. Há outras que misturam a ação dos jovens e a política, o que é benéfico, pois eles estão distanciados dela, e essas experiências os aproximam e refrescam a ação política. Vejo com muito otimismo. Teríamos que falar de grandes movimentos sociais, como os do Brasil, do México, os vinculados ao zapatismo etc., os quais, mesmo sem colocar no centro a relação comunicação e educação, levaram o assunto muito a sério. Na Argentina, há organizações políticas que não são partidos políticos e atuam através do uso da comunicação e educação. Eu trabalho muito com a localização de filhos de desaparecidos, cuja questão ligada aos meios de comunicação é levada muito a sério, o que, do ponto de vista da educação popular, é sumamente interessante.

C \& E: Para encerrar gostaria de pedir o relato de uma experiência que você considere significativa em comunicação e educação.

Huergo: Há uma rádio comunitária campesina, perto de Santiago do Chile, cujo trabalho me pareceu muitíssimo interessante, fundamentalmente relacionado com o reconhecimento de diferentes antagonismos sociais, com uma programação vinculada à questão de gênero e às questões técnicas. Ou seja, o foco é para aqueles que falam; é a existência de uma rádio comunitária, além da criação de um programa educativo. É interessante não pensar mais em termos de mensagens, mas sim em conjuntos textuais. São textos que utilizam a voz, a imagem, a música, os objetos etc. Então se pode dizer que há múltiplas mensagens superpostas, que conformam um meio. O meio também é um conjunto textual para além das suas mensagens isoladas. Assim, vejo as rádios 
comunitárias como conjuntos textuais. Na Argentina, a rádio livre de Rosário também tem um trabalho interessantíssimo vinculado a outro movimento de jovens que se chama Vagância, formado por um grupo de meninos muito pobres. Eles tiveram inicialmente ligação com a rádio, mas também com a educação escolar e popular, e se exercitam na música de rua. Esses jovens vão procurando formas de expressão que criem laços de solidariedade, assim como quem mora na cidade de Misiones, perto de Iguaçu, que produzem uma revista intitulada $C O C U$ e um projeto artístico chamado Alterado. Eles se expressam através da cultura e do teatro. $\mathrm{O}$ resultado foi um incremento no número de escritores, pintores e músicos em uma comunidade de vinte mil habitantes, os quais passaram a se articular com processos de capacitação de professores - assim, sem abandonar a cultura juvenil, foram se desenvolvendo, chegando até a criticá-la. São os próprios jovens que estimulam os alunos a escreverem contos, poesias. Veja, então, como é contraditório e como envolvem políticas educacionais, ambientais e comunicativas. Políticas juvenis que se articularam com a rádio comunitária e com movimentos criadores de cultura.

Resumo: Nesta entrevista, o diretor do Centro de Comunicação e Educação da Universidade Nacional de La Plata, o pensador argentino Jorge Huergo, expõe como o reconhecimento de mundo cultural é realizado mediante práticas de comunicação e educação em favor de um trabalho e de um encontro cultural, privilegiando as identidades, as formas de circulação dos saberes, o vínculo com os espaços e as formas de educação sociais. Huergo demonstra como isso nos mobiliza e nos põe em contato com as culturas juvenis e suas manifestações. Seu trabalho com educação popular, nas áreas rural, aborígine e urbana da América Latina, evidencia como é a relação entre comunicação e educação, vinculada ao mundo cultural e ao horizonte político, e com a criação de espaços e de possibilidade de comunicação através da formação, em um contexto composto de sentidos, meios de comunicação e tecnologia.

Palavras-chave: comunicação e educação, cultura juvenil, identidade, novas tecnologias.
Abstract: In this interview, the director to the Universidade Nacional de La Plata Communication and Education Center, the Argentine thinker Jorge Huergo, exposes how the cultural world recognition is made with communication and education practices on behalf of a cultural work and meeting, privileging identities, knowledge circulation manners, the vinculum with spaces and ways of social education. Huergo demonstrates how that mobilizes and puts us in contact with juvenile cultures and its manifestations. His work with popular education in Latin American rural, aborigine and urban areas makes clear how the relationship of communication and education is connected to the cultural world and political horizon, and with the creation of spaces and the possibility of communication through the formation, in a context composed of senses, media and technology.

Keywords: communication and education, juvenile culture, identity, new technologies. 


\section{Lições de nossa mãe África}

Fábulas africanas divertem e educam ao mesmo tempo, ensinam o respeito aos mais velhos, a importância de se valorizarem as tradições, conferem sentido aos aspectos cotidianos da vida e ajudam a compreender os componentes que tanto contribuíram para a formação cultural brasileira.
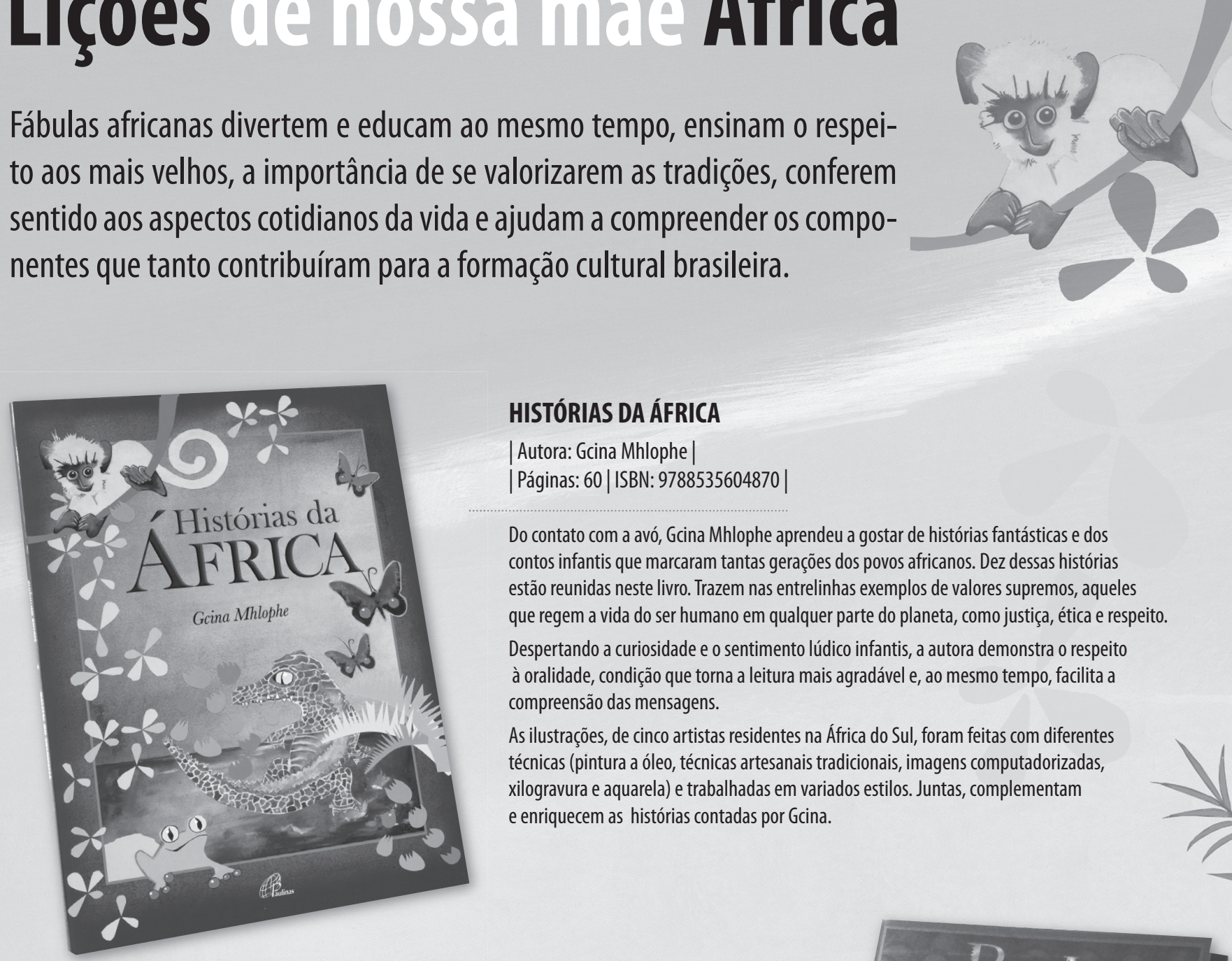

HISTÓRIAS DA ÁFRICA

|Autora: Gcina Mhlophe|

| Páginas: 60 | ISBN: 9788535604870 |

Do contato com a avó, Gcina Mhlophe aprendeu a gostar de histórias fantásticas e dos contos infantis que marcaram tantas gerações dos povos africanos. Dez dessas histórias estão reunidas neste livro. Trazem nas entrelinhas exemplos de valores supremos, aqueles que regem a vida do ser humano em qualquer parte do planeta, como justiça, ética e respeito. Despertando a curiosidade e 0 sentimento lúdico infantis, a autora demonstra o respeito à oralidade, condição que torna a leitura mais agradável e, ao mesmo tempo, facilita a compreensão das mensagens.

As ilustrações, de cinco artistas residentes na África do Sul, foram feitas com diferentes técnicas (pintura a óleo, técnicas artesanais tradicionais, imagens computadorizadas, xilogravura e aquarela) e trabalhadas em variados estilos. Juntas, complementam e enriquecem as histórias contadas por Gcina.

\section{RUA LUANDA}

| Autor: Edimilson de Almeida Pereira | Ilustrador: Rubem Filho

| Páginas: 40| ISBN: 9788535620252 |

Onde fica Rua Luanda? É possível vê-la no mapa? Não, não tem existência física; não pertence a nenhuma cidade ou país. É lugar feito de surpresas e de encantos. $\mathrm{Na}$ verdade, só a encontra quem deseja aprender as diferentes maneiras de as pessoas viverem. Ela faz parte da imaginação de todos que acreditam na fraternidade e na convivência harmoniosa entre as pessoas.

Edimilson reúne dezoito poemas que ressaltam exatamente a importância desses valores supremos que tornam a vida mais bela e mais humana. 0s textos, quase cantigas, nos ensinam a viajar para além dos lugares desenhados nos mapas, remetem à cultura afrodescendente, seja pela escolha vocabular, seja pela referência a Luanda, capital da República da Angola, país da costa ocidental da África. As belas ilustrações de Rubem Filho trazem muitos elementos africanos, quer nas cores quentes empregadas, quer nos detalhes.

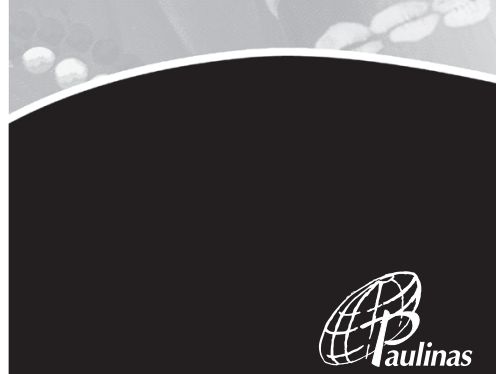

À venda na Rede Paulinas de Livrarias Se preferir, ligue 08007010081 ou acesse www.paulinas.org.br 